\title{
The vulnerable microcirculation in the critically ill pediatric patient
}

\author{
J. W. Kuiper ${ }^{1 *}$ (D, D. Tibboel ${ }^{1}$ and C. Ince ${ }^{2}$
}

\begin{abstract}
In neonates, cardiovascular system development does not stop after the transition from intra-uterine to extra-uterine life and is not limited to the macrocirculation. The microcirculation (MC), which is essential for oxygen, nutrient, and drug delivery to tissues and cells, also develops. Developmental changes in the microcirculatory structure continue to occur during the initial weeks of life in healthy neonates. The physiologic hallmarks of neonates and developing children make them particularly vulnerable during critical illness; however, the cardiovascular monitoring possibilities are limited compared with critically ill adult patients. Therefore, the development of non-invasive methods for monitoring the $\mathrm{MC}$ is necessary in pediatric critical care for early identification of impending deterioration and to enable the initiation and titration of therapy to ensure cell survival. To date, the MC may be non-invasively monitored at the bedside using hand-held videomicroscopy, which provides useful information regarding the microcirculation. There is an increasing number of studies on the MC in neonates and pediatric patients; however, additional steps are necessary to transition MC monitoring from bench to bedside. The recently introduced concept of hemodynamic coherence describes the relationship between changes in the MC and macrocirculation. The loss of hemodynamic coherence may result in a depressed $M C$ despite an improvement in the macrocirculation, which represents a condition associated with adverse outcomes. In the pediatric intensive care unit, the concept of hemodynamic coherence may function as a framework to develop microcirculatory measurements towards implementation in daily clinical practice.
\end{abstract}

Keywords: Microcirculation, Pediatrics, Hemodynamic coherence

\section{Background}

The cardiorespiratory system delivers oxygen and nutrients to meet oxygen and nutrient demands to support cellular and organ function. Hemodynamic monitoring is vital to identify changes in clinical conditions and evaluate interventions. It is important that hemodynamic monitoring is easily applied, reproducible, quantitative, and warns the physician before hemodynamic deterioration leads to cellular and organ injury. In addition to hemodynamic monitoring, a thorough understanding of physiology and pathophysiology is important in the care of critically ill patients. However, the pediatric intensivist and anesthesiologist face specific age- and developmentrelated problems, such as different body proportions, increased metabolic rate, and reduced respiratory and

\footnotetext{
* Correspondence: j.kuiper@erasmusmc.nl

${ }^{1}$ Intensive Care and Department of Pediatric Surgery, Erasmus Medical Center - Sophia Children's Hospital, Postbox 2040, 3000 CA Rotterdam, The Netherlands

Full list of author information is available at the end of the article
}

cardiovascular reserves, which makes the care of these patients particularly challenging.

This review focuses on the role of monitoring the microcirculation (MC) in (not yet) hemodynamically unstable pediatric patients and the specific problems that pediatric intensivists and anesthesiologists face on a daily basis in the care of this heterogeneous patient group. Cardiovascular development, the role of oxygen during development in the pediatric population, and the role of the MC are described. The specific problems encountered during hemodynamic instability, the limitations of cardiovascular monitoring, and how monitoring the MC may aid in decision making when initiating or evaluating therapies are subsequently discussed. In this context, we focus on the recently introduced concept of hemodynamic coherence $(\mathrm{HC})$, which may provide a framework for future decision-making. $\mathrm{HC}$ describes the relationship between the MC and the macrocirculation. When $\mathrm{HC}$ is present, improvements in the macrocirculation will 
lead to improvements in the MC. However, an optimally functioning macrocirculation does not guarantee an adequate microcirculatory perfusion. In specific situations, such as sepsis, $\mathrm{HC}$ is lost and despite an improved macrocirculation, the $\mathrm{MC}$ may remain dysfunctional. Furthermore, when attempts to improve the macrocirculation do not improve the $\mathrm{MC}$, additional interventions may worsen the MC [1]. The review concludes with a discussion regarding microcirculatory targeted therapy in the future.

\section{Cardiovascular development}

Cardiovascular development in children is a highly complex process. Major changes with important physiological consequences occur in the initial hours to days following birth. Further growth and development during the neonatal period and infancy change the physiology much less dramatically and the cardiovascular physiology begins to more closely resemble the adult physiology. The physiology in younger children continues to change but the physiology of older children becomes similar to adult physiology. Cardiovascular development affects important physiological parameters, such as the pulmonary and systemic vascular resistance (SVR), ventricular stroke volume, organ blood flow, and heart rate and thus compensatory mechanisms [2].

The transition from fetal to extra-uterine life is a complex process that affects nearly every organ; however, major changes predominately occur in the cardiovascular system. Fetal life is characterized by the presence of the low resistance placental circulation and fetal communication, the ductus arteriosus, the ductus venosus, and the foramen ovale, as well as development in a relatively hypoxic environment with high hematocrit. The left and right ventricular pressures are equal with right heart predominance [2]. In addition, the pulmonary vascular resistance is high and changes during fetal life, whereas a substantial decrease in the vascular resistance occurs after birth $[3,4]$. Of note, the pulmonary vascular reactivity to oxygen increases during pregnancy, with potential implications for pulmonary hypertension and right to left shunting after birth $[3,4]$. After clamping the umbilical cord, the fetal circulation rapidly transforms into an adult circulation. Under the influence of various hormones released during labor and delivery, as well as the removal of the low resistance placental circulation, the SVR suddenly increases, whereas the pulmonary vascular resistance decreases [2]. These changes result in increased pulmonary blood flow and increased left ventricle preload. The result is an increased left ventricular output that peaks $2 \mathrm{~h}$ after birth [5, 6]. Following the closure of the foramen ovale, the ductus arteriosus closes, which partially explains the decrease in the left ventricular output in the $22 \mathrm{~h}$ after the peak left ventricular output [2]. The closure of the ductus arteriosus is typically complete after $48-72 \mathrm{~h}$, although it may be delayed when shunting across the ductus persists [6]. The separation of the pulmonary and systemic circulation leads to an arterial oxygen saturation increase from 60-70 \% one minute after birth to near normal adult values after $8-10$ minutes $[5,7,8]$. The ventricles of newborns are less compliant with decreased diastolic function; moreover, the response to inotropes and volume loading are less pronounced and an increased afterload is less well tolerated [9]. Both the SVR and left ventricular afterload increase; thus, there is limited inotropic reserve.

Following the initial drastic changes in the cardiovascular physiology after birth, the cardiovascular system continues to change more slowly and the differences between child physiology and adult physiology become less clear [10]. In the first few years following birth, the heart adapts to the new preload and afterload and the inotropic reserve capacity increases [9]. After its initial increase, the SVR decreases, particularly in the first 5 years of life. In this same period, the stroke volume index increases and stabilizes to adult values at approximately 5 years of age. The stroke volume continues to increase until 13 years of age. The cardiac index increases in the first 3 years but decreases after 5 years of age to adult levels after 10 years of age [10].

The normal transition and cardiovascular development are well-balanced processes; however, the physiological remnants of fetal life and the consequences of a developing cardiovascular system may become obvious when the normal physiology is under pressure and compensatory mechanisms are needed. In critically ill children in the first years of life, the oxygen and metabolic demands are increased, exhibit less variation, and lack a hypermetabolic response [11]. During sepsis in adults, despite an increased end diastolic volume, septic cardiac dysfunction causes an increased end systolic volume and the stroke volume index remains within the normal range [12]. In addition, the heart rate and cardiac index both increase during sepsis in adults $[12,13]$. In children with septic shock, despite impaired contractility, the left ventricular preload presumably does not increase and compensation mainly depends on an increasing heart rate. This is limited by the normally high heart rate in neonates and infants and, to a lesser extent, in children past infancy [14]. However, more recent studies demonstrate that increases in the cardiac output $(\mathrm{CO})$ can be achieved by an increased stroke volume [15-18]. Cardiac function in neonates and infants is characterized by an increased contractile state, increased sensitivity to afterload, and increased oxygen demands at an increased heart rate or preload state, which is less clear for children $[15,16]$. In contrast to adults, in which a high cardiac index and low SVR are the hallmarks of sepsis, the presentation of pediatric patients differs. In central venous catheter-related sepsis $94 \%$ of the pediatric 
patients presented with high cardiac index and low SVR but in community acquired sepsis $86 \%$ presented with a low to normal cardiac index and variable SVR [19].

\section{Assessment of cardiovascular compromised pediatric patients}

The currently available techniques to assess cardiovascular compromised pediatric patients and evaluate therapy include both invasive techniques, such as the direct measurement of $\mathrm{CO}$, and non-invasive techniques, such as echocardiography and physical examination. Furthermore, central and mixed venous saturation have been used as surrogate markers for the adequacy of $\mathrm{CO}$. The capillary refill time, peripheral temperature, and serum lactate levels are used as markers of tissue perfusion, and measurements of the lung water and "fluid responsiveness" may be used to guide fluid therapy [20]. Persistently low $\mathrm{CO}$ measurements in septic children are associated with increased mortality [21, 22].

The clinical estimation of $\mathrm{CO}$ is unreliable, which has been demonstrated in infants and children following cardiac surgery [23]. The gold standard for invasive measurement of $\mathrm{CO}$ is the pulmonary artery catheter, which is not widely used in children [24, 25], not only because of its size but also because pulmonary artery catheter usage in adults has not been demonstrated to be effective and is associated with an increased length of stay, mortality, and costs [26-28]. Less invasive alternatives have been developed, such as Doppler signals, dilution-based methods, and bioimpedance. Following its use for approximately 20 years in pediatrics, Lemson et al. validated transpulmonary thermodilution in lambs as a precise method to measure $\mathrm{CO}[24,25,29]$; however, it requires both central venous and arterial access and is typically unsuitable for infants under $3.5 \mathrm{~kg}$. Moreover, the validity and relevance of CO measurement using transpulmonary dilution techniques in patients with intra-cardiac or extra-cardiac shunts is questionable. Echocardiographic estimations of $\mathrm{CO}$ are highly operator-dependent, require extensive training, and are, therefore, often inaccurate; moreover, research in children focuses on different techniques and its validation under different conditions [20,30]. Venous oximetry comprises an invasive measurement; however, it is used as an alternative for invasively measured CO. Central venous saturation represents a poor surrogate for determining the adequacy of CO [31]. Central venous saturation is typically measured in the superior vena cava because measurements from the inferior vena cava may provide deviating results [32, 33]. A further complicating feature in the interpretation of venous saturation is the matter of high mixed venous saturations in critically ill patients as a result of impaired oxygen extraction and cardiac and microcirculatory shunts [9, 20, 34]. Thus, it is unclear whether central venous saturation measurements have additional value in pediatric critical care; nevertheless, central venous saturation is part of the Surviving Sepsis Campaign protocol for children [20, 35]. In summary, $\mathrm{CO}$ measurements in children are difficult and are much less frequently performed compared with adults.

For the assessment of tissue perfusion, the capillary refill time, temperature, and serum lactate concentrations are used. A prolonged capillary refill time may indicate an early warning sign of cardiovascular failure. Despite a predictive value in an emergency department [36, 37], in an intensive care unit, the capillary refill time exhibits no correlation with hemodynamic variables, such as the cardiac index, central venous pressure, stroke volume index, and SVR, in pediatric patients following cardiac surgery [38]. In the general pediatric intensive care unit population, only a severely prolonged capillary refill time correlates with the stroke volume index and lactate concentration; however, this correlation is relatively weak [38]. In this same study, Tibby et al. demonstrated that the coreperipheral temperature gap closely correlated with the capillary refill time; however, there was no correlation with the previously described hemodynamic parameters [38]. Lactate is used as a marker of tissue perfusion but increased lactate levels may also arise from increased production via activated white blood cells, inflammatory mediator-accelerated glycolysis and catecholaminestimulated muscle, or decreased clearance during mitochondrial dysfunction or liver failure [39, 40]. In various circumstances, a high serum lactate concentration has prognostic value in a pediatric intensive care unit [41-45]. To date, however, there is no evidence in pediatric patients indicating improved outcome when a reduction in lactate levels is used as a target in goal-directed therapy $[39,46]$.

Taken together, no bedside tool to date reliably informs the pediatric intensivist or pediatric anesthesiologist regarding oxygen delivery in critically ill pediatric patients or is able to warn the clinician of impending cardiovascular deterioration. Most therapeutic interventions aim to improve oxygen delivery to the tissues and cells. However, the effect of blood transfusions to optimize the oxygencarrying capacity of the circulation, fluid administration, inotropes, and vasopressors is measured using the previously described (macrocirculatory) parameters as end points. However, these interventions only improve oxygen delivery to the tissues and cells when $\mathrm{HC}$ is preserved, i.e., the effects on the macrocirculatory parameters are also effective in restoring the $\mathrm{MC}$ [1]. Also, the effects of these interventions on the $\mathrm{MC}$ are not yet clinically monitored at the bedside.

\section{Monitoring of the pediatric MC}

The final steps in oxygen delivery by the cardiovascular system are to deliver oxygen to the MC and diffusion of 
oxygen to cells. Hand-held videomicroscopy, utilizing orthogonal polarization, spectral, sidestream dark field, and incident dark field imaging techniques, may readily be used to visualize the $\mathrm{MC}$ at the bedside. Currently, consensus meetings are being held to determine the optimal method to analyze and obtain functional microcirculatory parameters from the images obtained by hand-held videomicroscopy. Several studies in pediatric patients have addressed the microcirculation in various disease states and different age groups [47-49].

The MC consists of vessels with a diameter smaller than $100 \mu \mathrm{m}$ : arterioles, capillaries, and venules [50]. An optimally functioning macrocirculation does not guarantee adequate microcirculatory perfusion if therapeutic interventions do not result in a coherent improvement of the MC. Parameters such as the arteriolar tone, hemorheology, endothelial function, and capillary patency also determine flow in the MC [50]. In adult patients with severe sepsis and traumatic hemorrhagic shock, the loss of coherence between the resuscitated macrocirculation and MC has been demonstrated to be the most sensitive and specific hemodynamic indicator associated with increased multiorgan failure and mortality [51-56]. In critically ill children with sepsis, a persistently altered MC has been associated with increased mortality [48]. Indices of microcirculatory blood flow may also serve as early indicators of decreased perfusion of the $\mathrm{MC}$ and potentially warn clinicians regarding the development of multi-organ failure [57-59]. Thus, MC measurement must be considered a valuable extension of current hemodynamic monitoring techniques $[9,60]$.

Readily accessible sites for MC measurements using hand-held videomicroscopy include the buccal and sublingual MC. In (preterm) neonates, the reduced thickness of the skin enables transcutaneous measurements of the MC [61-63]. Orthogonal polarization spectral imaging was the first hand-held videomicroscopy technique that visualized the MC and was succeeded by sidestream dark field imaging in 2007 [64-66]. Recently, the CytoCam, which is based on incident dark field imaging, was introduced [67]. The CytoCam uses a different illumination technique and is smaller and lighter and has a higher optical resolution [68]. In preterm neonates, transcutaneous measurements using an incident dark field have been demonstrated to be superior to a sidestream dark field in terms of the detected number of vessels, and the perfusion of the vessels could also be more accurately detected [68]. Moreover, the imaging quality scores for illumination, focus, and pressure were better for the incident dark field compared with sidestream dark field imaging [68].

To differentiate capillaries from venules, in general, a cutoff value of $20 \mu \mathrm{m}$ is used [69]. In preterm and term neonates, however, small vessels are, on average, $8.4 \mu \mathrm{m}$; moreover, in term neonates, the capillary diameter does not exceed $10 \mu \mathrm{m}$ [47]. Thus, in pediatric studies, a general cutoff value of $10 \mu \mathrm{m}$ is used [48, 49, 70-74]. Ideally, multiple measurements should be performed per organ in at least three different sites [69]. To describe the MC, descriptive parameters such as perfused vessel density, as a measure of functional capillary density, have been introduced. The functional capillary density represents the functional volume of flowing red blood cell (RBC)-filled capillaries per unit area of tissue. Additional parameters include the proportion of perfused vessels and total vessel density [69]. The measurement of the flow is the major technical challenge, which is why a semi-quantitative index referred to as the microvascular flow index has been developed $[75,76]$. It must be noted that this index was specifically designed for sepsis and may not be well suited for other states of hypoperfusion, such as heart failure with a progressive decrease in flow. Depending on the disease state, the MC may be very heterogeneous, particularly during distributive shock as exhibited in sepsis [59]. To this end, a heterogeneity index was introduced to describe this property of the MC [59, 69]. A recent paper provides a comprehensive review regarding the current state-of-the-art of handheld videomicroscopy and the difficulties encountered in the application of this technique [77]. Nevertheless, visualization of the $\mathrm{MC}$ has been demonstrated to be feasible and has introduced a novel field of research and a new modality for non-invasive hemodynamic monitoring in the pediatric population (Tables 1 and 2).

\section{The MC in critically ill pediatric patients}

Several studies in pediatric patients have assessed the $\mathrm{MC}$ in different clinical settings and disease states. Most studies have been performed in preterm and term neonates in which the physiological differences with the adult population vary most. A smaller selection of studies have been performed in the pediatric intensive care unit, with a very heterogeneous group in terms of age, physiology, and underlying diagnoses.

\section{Studies in neonates}

The MC changes in the first weeks of life in healthy term and preterm infants. In various disease states and different age groups, changes in the $\mathrm{MC}$ following interventions have been described (Table 1). Changes in the MC have been associated with poor outcomes in various disease states. Monitoring the MC was first reported in 2002 in preterm and term neonates during the first 5 days of life [47]. The authors demonstrated that the RBC velocity increased in preterm infants during the first 5 days of life and was correlated with a decrease in hemoglobin levels [47]. In the first weeks of life of term and preterm infants, the MC changes likely because of an adaptation to extra-uterine life. In neonates, the functional capillary density decreases in the first week of life $[62,71]$. In 
Table 1 Neonatal studies of the microcirculation using orthogonal polarization spectral, sidestream dark field or incident dark field imaging

\begin{tabular}{|c|c|c|c|c|c|c|}
\hline Study & $N$ & Age group & Technique/site & Disease & Intervention & Outcome \\
\hline $\begin{array}{l}\text { Genzel-Boroviczény } \\
\text { et al. } 2002 \text { [47] }\end{array}$ & 37 & Preterm/term & OPS/skin & - & - & $\begin{array}{l}\text { Feasibility study; RBC velocity increases in preterm infants, } \\
\text { correlated with a decrease in } \mathrm{Hb}\end{array}$ \\
\hline $\begin{array}{l}\text { Genzel-Boroviczény } \\
\text { et al. } 2004 \text { [61] }\end{array}$ & 13 & Preterm & OPS/skin & Anemia & $\begin{array}{l}\text { RBC } \\
\text { transfusion }\end{array}$ & FCD improves at least $24 \mathrm{~h}$ \\
\hline Kroth et al. 2008 [62] & 25 & Preterm & OPS/skin & - & - & $\begin{array}{l}\text { FCD decreases in first } 4 \text { weeks of life, correlated with } \mathrm{Hb} \\
\text { levels and incubator temperature }\end{array}$ \\
\hline Top et al. 2009 [70] & 14 & $0-18$ days & OPS/buccal & $\begin{array}{l}\text { Respiratory } \\
\text { failure }\end{array}$ & - & $\begin{array}{l}\text { FCD is decreased compared with non-ventilated controls, } \\
\text { VA-ECMO improves FCD }\end{array}$ \\
\hline $\begin{array}{l}\text { Weidlich et al. } \\
2009 \text { [87] }\end{array}$ & 25 & Preterm & OPS/skin & Infection & - & FCD decreases 1 day before clinical signs of infection \\
\hline Hiedl et al. 2010 [81] & 25 & Preterm & SDF/skin & PDA & PDA closure & $\begin{array}{l}\text { Reduces FCD with PDA, recovery of FCD after closure of } \\
\text { PDA }\end{array}$ \\
\hline $\begin{array}{l}\text { Ergenekon et al. } \\
2011 \text { [63] }\end{array}$ & 15 & Term & SDF/skin & Polycythemia & PET & PET improves FCD \\
\hline $\begin{array}{l}\text { D'Souza et al. } \\
2011[111]\end{array}$ & 115 & Preterm/term & OPS/skin & LBW & - & $\begin{array}{l}\text { FCD is increased in LBW compared with normal birth } \\
\text { weight infants }\end{array}$ \\
\hline Top et al. 2012 [73] & 21 & Term & OPS/buccal & $\begin{array}{l}\text { Respiratory } \\
\text { failure }\end{array}$ & VA-ECMO & $\begin{array}{l}\text { FCD is maintained but not immediately improved } \\
\text { following initiation of VA-ECMO }\end{array}$ \\
\hline $\begin{array}{l}\text { Ergenekon et al. } \\
2013 \text { [112] }\end{array}$ & 14 & Term & SDF/skin & Asphyxia & $\mathrm{TH}$ & $\begin{array}{l}\text { Flow is impaired compared with controls, flow improves } \\
\text { after re-warming }\end{array}$ \\
\hline $\begin{array}{l}\text { Alba-Alejandre } \\
\text { et al. } 2013 \text { [113] }\end{array}$ & 47 & Term & OPS/skin & Infection & & Flow is decreased during infection, no difference in FCD \\
\hline $\begin{array}{l}\text { Schwepcke et al. } \\
2013[114]\end{array}$ & 21 & Preterm & SDF/skin & Hypotension & & $\begin{array}{l}\text { FCD is increased in hypotensive neonates } 6 \mathrm{~h} \text { after birth; } \\
\text { it subsequently normalized to normotensive control levels }\end{array}$ \\
\hline $\begin{array}{l}\text { Raghuraman et al. } \\
2013 \text { [115] }\end{array}$ & 141 & Preterm/term & OPS/skin & - & - & $\begin{array}{l}\text { FCD is increased in twins compared with singletons, low } \\
\text { birth weight was associated with lower FCD }\end{array}$ \\
\hline Buijs et al. 2014 [74] & 56 & Term & SDF/buccal & $\mathrm{CDH}$ & - & $\begin{array}{l}\text { Loss of hemodynamic coherence; severely impaired MC } \\
\text { after dopamine predicts need for the addition of } \\
\text { (nor)epinephrine }\end{array}$ \\
\hline $\begin{array}{l}\text { Van den Berg et al. } \\
2014[116]\end{array}$ & 28 & Term & SDF & - & - & $\begin{array}{l}\text { Buccal measurements of vessel density are reproducible, } \\
\text { cutaneous are not reproducible }\end{array}$ \\
\hline $\begin{array}{l}\text { Van Elteren et al. } \\
2015 \text { [68] }\end{array}$ & 20 & Preterm & SDF/IDF & - & - & $\begin{array}{l}\text { IDF is superior compared with SDF in vessel visualization, } \\
\text { visualization of perfusion, and image quality score }\end{array}$ \\
\hline
\end{tabular}

$C D H$ congenital diaphragmatic hernia, $F C D$ functional capillary density, $H b$ hemoglobin, IDF incident dark field imaging, $L B W$ low birth weight, OPS orthogonal polarization spectral imaging, PDA persistent ductus arteriosus, PET partial exchange transfusion, $R B C$ red blood cell, SDF sidestream dark field imaging, $T H$ therapeutic hypothermia, VA-ECMO veno-arterial extracorporeal membrane oxygenation

preterm infants, the functional capillary density of the skin decreases during the first month, which is correlated with the physiological decrease in hemoglobin levels and environmental incubator temperature [62]. The functional capillary density of both the buccal mucosa in term and the skin in preterm infants decreases in the first week, which suggests that these changes represent adaptation to extra-uterine life rather than disturbed development as a result of premature birth [62, 71]. Early research suggests that the $\mathrm{MC}$ of the skin resembles that of adults at the age of 3 months [78]. Whether this is true for all microvascular beds remains elusive. Ambient temperature, an increase in oxygen consumption because of the increased work of breathing and gastrointestinal function, and high levels of fetal hemoglobin in the first months of life may be compensated for by increased macrocirculatory and microcirculatory blood flow [9]. The high functional capillary density in the first week of life may be attributed to increased $\mathrm{CO}$ and high hematocrit levels, although autoregulation of the $\mathrm{MC}$ may also play a role $[9,79,80]$.

In various disease states, changes in the MC have been described following interventions (Table 1). In anemic preterm infants, the administration of a blood transfusion resulted in a parallel increment in the functional capillary density, which lasted at least $24 \mathrm{~h}$ [61]. Decreasing hematocrit with a partial exchange transfusion in neonates 
Table 2 Pediatric studies of the microcirculation using orthogonal polarization spectral or sidestream dark field

\begin{tabular}{|c|c|c|c|c|c|c|}
\hline Study & $N$ & Age group & Technique/site & Disease & Intervention & Outcome \\
\hline Top et al. 2010 [71] & 45 & $0-3$ years & OPS/buccal & - & - & FCD decreases after the first week of life \\
\hline Top et al. 2011 [48] & 18 & $0-15$ years & OPS/buccal & Septic shock & - & $\begin{array}{l}\text { FCD does not differ on day 1, non-survivors have } \\
\text { persistently low FCD }\end{array}$ \\
\hline Top et al. 2011 [72] & 8 & $0-3$ years & OPS/buccal & Respiratory failure & iNO & $\begin{array}{l}\text { iNO increases FCD without altering macrocirculatory } \\
\text { parameters }\end{array}$ \\
\hline Paize et al. 2012 [117] & 60 & $0-6$ years & SDF/sublingual & MCD & - & $\begin{array}{l}\text { FCD is decreased at admission; however, it } \\
\text { increases when MCD resolves. } \mathrm{HI} \text { is correlated with } \\
\text { duration of ventilation }\end{array}$ \\
\hline Buijs et al. 2014 [49] & 20 & $0-16$ years & SDF/buccal & Cardiac arrest & $\mathrm{TH}$ & $\begin{array}{l}\text { FCD and flow are impaired during } \mathrm{TH} \text {; however, } \\
\text { they recover after re-warming. Severe impairment } \\
\text { was associated with mortality }\end{array}$ \\
\hline Nussbaum et al. 2015 [85] & 40 & $0-3$ years & SDF/ear & $\begin{array}{l}\text { Cardiac surgery/ } \\
\text { catheterization }\end{array}$ & - & $\begin{array}{l}\text { Transient reduction in MFI and PVD after cardiac } \\
\text { surgery with and without cardiopulmonary bypass }\end{array}$ \\
\hline Schinagl et al. 2016 [86] & 37 & Unknown & SDF/buccal & Anemia & Blood Tx & $\begin{array}{l}\text { Transfusion increased TVD with decreased RBC } \\
\text { velocity, particularly during infection }\end{array}$ \\
\hline
\end{tabular}

FCD functional capillary density, $H I$ heterogeneity index, iNO inhaled nitric oxide, MCD meningococcal disease, MFI microvascular flow index, OPS orthogonal polarization spectral imaging, $P V D$ perfused vessel density, $R B C$ red blood cell, SDF sidestream dark field imaging, $T H$ therapeutic hypothermia, $T V D$ total vessel density, $T x$ transfusion

with polycythemia increased the microvascular flow index for small and larger vessels, which suggests an optimal hematocrit for the maximal functional capillary density and microvascular flow index. In neonates with severe respiratory failure, the functional capillary density was decreased compared with non-ventilated controls; however, it significantly increased as the clinical conditions improved and the patients were removed from extracorporeal membrane oxygenation (ECMO) support [70]. The observed improvement in the functional capillary density was most likely a result of a combination of the overall clinical improvement, administration of vasodilators, and decreased levels of vasopressors [70]. During ECMO for severe respiratory failure, the functional capillary density, microvascular flow index, and heterogeneity index did not improve following the initiation of ECMO, although ECMO appeared to prevent the further deterioration of the $\mathrm{MC}$ [73]. Preterm infants with a patent ductus arteriosus (PDA) with a left to right shunt that resulted in decreased peripheral perfusion had a lower functional capillary density compared with preterm infants without a PDA [81]. Interestingly, there appeared to be a shift in the microcirculatory flow to relatively smaller vessels in the PDA group [81]. Correction of the PDA resulted in an improvement of the functional capillary density to control values and the shift to relatively more small vessels disappeared [81]. Dopamine improved the macrocirculation in neonates with $\mathrm{CDH}$; however, it did not hemodynamically coherent improve the $\mathrm{MC}$, and the $\mathrm{MC}$ also did not improve after the addition of epinephrine or norepinephrine, whereas these treatments did increase the heart rate and blood pressure [74]. Adrenergic vasopressor treatment may be deleterious for the MC [82], and similar results have been demonstrated in adults [83, 84]. It remains unclear how the MC in critically ill neonatal patients may be optimally improved. To date, only blood transfusion during anemia has been reported to improve the $\mathrm{MC}$ in terms of increasing the functional capillary density.

\section{Studies in pediatric patients}

Most studies have been performed in neonates, but several studies have focused on older children as well (Table 2). In patients ranging from 0-3 years old, Top et al. [71] reported that functional capillary density changes in the first week, after which there was no correlation between age and the functional capillary density. Also in patients ranging from $0-3$ years old, cardiac surgery with or without cardiopulmonary bypass resulted in a transient reduction of the microvascular flow index and functional capillary density [85]. Only two studies in children demonstrated changes in the $\mathrm{MC}$ after an intervention. In eight patients with hypoxemic respiratory failure, five of whom suffered from congenital diaphragmatic hernia, the buccal functional capillary density significantly improved following the initiation of inhaled nitric oxide (NO) [72]. Inhaled NO did not affect the systemic blood pressure, which makes the mechanism by which $\mathrm{NO}$ improves the $\mathrm{MC}$ unclear [72]. In anemic hematology or oncology patients, a blood transfusion increased the total vessel density but not to normal values [86]. In pediatric patients, similar to neonates, it remains unclear how to best improve the $\mathrm{MC}$ in terms of the functional capillary density. 


\section{Monitoring the MC to guide patient management}

The studies in pediatric critically ill patients have mainly been observational in nature, which provides vital information but does not guide the initiation or titration of therapy to improve the MC. One study indicated alterations in the $\mathrm{MC}$ that preceded clinical deterioration, and a limited number of studies have demonstrated prognostic value (Table 1). Nevertheless, monitoring the MC may provide valuable information regarding the loss of $\mathrm{HC}$. Four types of alterations in the MC have been identified that underlie the loss of $\mathrm{HC}$. Weidlich et al. [87] performed the first study that demonstrated MC measurements may be used to initiate therapy. This study indicated that the functional capillary density decreased one day before changes in the laboratory parameters and preceded the prescription of antibiotics in preterm infants. In septic pediatric patients, a persistently altered MC was prognostic for mortality and was demonstrated to be superior to the severity of the illness score using the pediatric risk of mortality 2 score in the prediction of mortality [48]. Buijs et al. [49] reported poor outcomes in pediatric patients with early buccal microcirculatory impairment during therapeutic hypothermia following cardiac arrest. Re-warming improved the impaired MC to control values; however, the functional capillary density of the vessels with a diameter of 11-100 $\mu \mathrm{m}$ and the microvascular flow index before the initiation of therapeutic hypothermia were significantly decreased in non-survivors [49]. Coherence between the systemic circulation and the $\mathrm{MC}$ is lost when improvements in systemic parameters are not reflected by improvements in the MC [1]. This issue may occur particularly in states of shock, inflammation, reperfusion, and infection, as well as resuscitation damage to normal cellular sensing mechanisms $[1,51-54,88]$. In adults, the loss of coherence predominately occurs in sepsis $[52,53,56]$. Loss of HC also occurs in pediatric patients. In neonates with congenital diaphragmatic hernia, increasing the mean arterial blood pressure with catecholamines did not improve the MC [74].

Four types of alterations in the $\mathrm{MC}$ have been delineated that may underlie the loss of HC (Fig. 1) [1]. The concept of hemodynamic coherence, including the four types that explain the loss of coherence, may become vital when measurements of the MC are ready to be translated into the clinical setting in the future. The four types of loss of coherence have been demonstrated during the previous decade, mainly in adult studies; however, they require further prospective evaluations in pediatric patients, particularly in terms of the effectiveness in improving patient outcome. In type 1, which is typically observed in sepsis, there is heterogeneity in the perfusion of the MC, with obstructed capillaries next to capillaries with normal flow (Fig. 1). The persistence of
Microcirculatory alterations associated with loss of hemodynamic coherence.
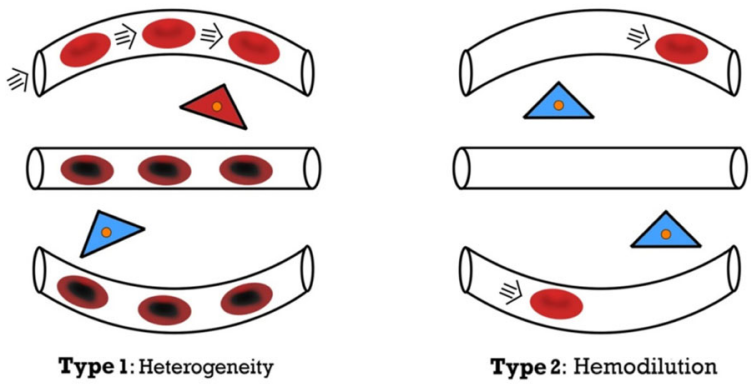

Type 2: Hemodilution
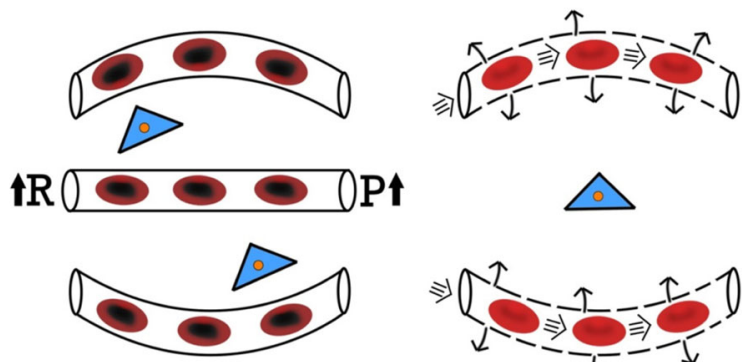

Type 3: Constriction/tamponade

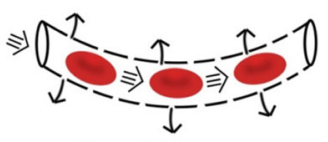

Type 4: Edema

Key: red and blue signify well-oxygenated red blood cells and tissue cells and cells with reduced oxygenation respectively.

Fig. 1 Microcirculatory alterations that underlie the loss of hemodynamic coherence between the macro- and microcirculations resulting in tissue hypoxia. Type 1 comprises a condition with a heterogeneous perfusion of the microcirculation as exhibited by septic patients with obstructed capillaries next to perfused capillaries, which results in a heterogeneous oxygenation of the tissue cells. Type 2 occurs as a consequence of hemodilution, with the dilution of microcirculatory blood resulting in the loss of RBC-filled capillaries and increasing the diffusion distance between oxygen carrying RBCs and tissue cells. Type 3 alterations result in a stasis of microcirculatory RBC flow induced by an increased arterial vascular resistance, vasopressor therapy, increased venous pressure, or hyperoxia. Type 4 alterations involve edema caused by capillary leak syndrome and results in an increased diffusive distance and reduced ability of oxygen to reach tissue cells. Adapted from [1]

this type of loss of coherence is associated with a poor outcome in adult sepsis $[51,56]$. In pediatric patients who require ECMO, type 1 alterations have been described, which were associated with poor outcome [48]. The heterogeneity index has been introduced to describe type 1 alterations [53]. Type 1 abnormalities warrant the administration of antibiotics and vasoactive agents (vasodilators) to promote the patency of the MC $[1,35]$, but prospective studies are needed. Type 2 is characterized by hemodilution, which is mainly caused by excessive fluid administration and results in the loss of RBC perfused vessels (Fig. 1). This type has predominately 
been described in patients who underwent cardiac surgery [89]. This issue may be corrected by blood transfusions to improve the hematocrit levels, which thereby increase the oxygen transport capacity of the microcirculation [90, 91]. Several studies have shown the ability of blood transfusions to improve the MC. Yuruk et al. [90] showed an increase in functional capillary density after blood transfusion, increasing hemoglobin levels from 7.1 to $8.5 \mathrm{~g} / \mathrm{dL}$, during cardiac surgery. Comparing transfusions with leukodepleted and non-leukodepleted RBCs in septic patients, Donati et al. [91] showed that increasing hemoglobin levels from 8.3 to $10.4 \mathrm{~g} / \mathrm{dL}$ with leukodepleted blood improved functional capillary density. This study also suggests that the quality of the transfused blood influences the increase in FCD. Recently, Schinagl et al. [86] showed in pediatric patients with hematological or oncological disease that RBC transfusion, increasing hemoglobin from 7.2 to $8.0 \mathrm{~g} / \mathrm{dL}$, improved functional capillary density. Although increasing blood hemoglobin levels may improve the microcirculation in various clinical settings, we do not suggest to change transfusion guidelines. The potential role of inhaled NO in RBC-induced capillary recruitment is unclear. Top et al. [72] showed an improvement of the microcirculation after inhaled NO in pediatric patients with hypoxic respiratory failure. In contrast, Trzeciak et al. [92] did not show improvement of the $\mathrm{MC}$ in patients with sepsis following inhaled NO. The effect of RBC transfusion on the MC is likely caused by increasing blood viscosity. In an animal model of anemia it has been shown that increasing the blood viscosity increases functional capillary density (FCD) [93]. The third type comprises the constriction/tamponade type, in which the flow in the MC is constricted (Fig. 1). Norepinephrine, which is advised for use in the treatment of sepsis [35], increases the blood pressure by vasoconstriction, although it simultaneously impairs the RBC flow in the MC [83, 84]. Inappropriate use of other vasopressors has also resulted in this effect [94]. Importantly, hyperoxia is also associated with type 3 alterations of the MC. In healthy volunteers, increasing the fraction of inspired oxygen decreases the sublingual functional capillary density [95]. In animal experiments, administration of hyperbaric oxygen decreased FCD and may be associated with what gives the appearance of maldistribution of perfusion in the MC [96]. Central venous pressures that exceed $12 \mathrm{mmHg}$ may reduce the perfusion of the $\mathrm{MC}$ by inducing tamponade, which likely occurs via an increase in the post-capillary pressure [97]. The final type occurs when a capillary leak, endothelial damage, and loss of glycocalyx barriers lead to edema formation with an increased diffusion distance (Fig. 1) [1]. This type may have been involved in patients with severe malaria treated with a liberal fluid strategy [98]. In a trial of pediatric patients with malaria or sepsis, this type of loss of coherence may partially explain the adverse outcome in the liberal fluid administration group [99, 100].

An altered MC may be the cause of injury or a marker of cellular injury, since various insults may cause $\mathrm{MC}$ dysfunction. Macrocirculatory dysfunction negatively affects the MC and local inflammation and hormonal actions also affect it $[1,101]$. In sepsis, endothelial cell injury and RBC injury may cause dysfunction of the MC. In the absence of injury, however, (iatrogenic) dysfunction of the MC can also occur, for example, following hemodilution or nor-epinephrine infusion $[1,83,84,101]$. Of special interest is the interaction between the MC and mitochondrial function, particularly during states of shock, sepsis, and resuscitation [102]. When mitochondrial dysfunction occurs, cells may fail to utilize oxygen regardless of the state of the MC [103]. Irrespective of the cause of dysfunction of the $\mathrm{MC}$, during an effective resuscitation of the macrocirculation, the MC should be simultaneously monitored to assure HC. When $\mathrm{HC}$ is lost, monitoring the $\mathrm{MC}$ and establishing the type of loss of $\mathrm{HC}$ can guide therapy. The concept of $\mathrm{HC}$ and the four types of alterations that may explain the loss of coherence are based on experience with monitoring the $\mathrm{MC}$ in the previous decade; however, this concept requires further prospective evaluations in children and adults. Larger studies, including observational studies and randomized trials, are needed to assess the effectiveness and patient outcome of interventions based on this concept.

\section{Microcirculatory-targeted therapy in the future}

Before measurement of the $\mathrm{MC}$ can become a part of the routine care of critically ill children, three central issues need to be addressed. First, larger observational studies are needed to further delineate the role of the MC in various disease states in critically ill children and observe the effect of interventions and outcome. International observational cohort studies have been performed in critically ill adults [104]. In randomized trials the effect of monitoring the $\mathrm{MC}$ and intervening in the $\mathrm{MC}$ on outcome should subsequently be examined. The second issue is the validation in observational studies and randomized trials of the concept of $\mathrm{HC}$ as a framework for bedside monitoring and decision-making in children and adults. Third, future research should focus on the translation from bench to bedside of monitoring the MC. Important research areas are, first, the determination of which functional parameters best describe the physiological (dys)function of the MC. Second, the image quality and analyses should be of high quality and automated to be instantaneously available at the bedside. Third, the establishment of the concept of $\mathrm{HC}$ as a framework for MC-targeted therapy at the bedside will require a 
hardware and software platform that integrates the monitoring of the macrocirculation with the MC.

Physiological and quantitative parameters based on the oxygen transport capacity of the $\mathrm{MC}$ will need to be introduced based on the classic MC literature related to oxygen transport to tissues. It is essential for the optimization of the oxygen carrying capacity of the $\mathrm{MC}$ to ensure proper convective flow, short diffusion distances, and a sufficient level of hematocrit $[105,106]$. For a complete functional description of MC images, four physiological parameters are needed. First, the available RBCs in the capillaries are defined by the tube hematocrit, which is measured from the volume of RBCs in the capillaries divided by the volume of the capillary $[105,106]$. Second, the oxygen delivery capacity is defined by the discharge hematocrit, which is the tube hematocrit that flows through the capillary per unit of time $[105,106]$. Third, the oxygen-releasing capacity of the MC to the tissues is necessary. This is described by the diffusive capacity of the MC (functional capillary density). Capillary blood flow is not equal in all capillaries and all capillaries are not necessarily filled by oxygen-carrying RBCs. This has been described by the heterogeneity index [53]. This microcirculatory variable may be more accurately defined by a quantitative assessment of the flow pattern distributions in the MC. With the current generation of hardware using computercontrolled imaging sensors, the measurements of these four parameters at the bedside are within reach.

These functional parameters will be of use to describe the type of loss of $\mathrm{HC}$ present at the bedside (Table 3) and initiate and titrate therapy. From current knowledge, a low discharge hematocrit associated with a low convective flow is indicative of hypovolemia and has been demonstrated to be effectively treated by fluid therapy. However, if the microcirculatory flow is normal or high, irrespective of the presence of clinical surrogates of hypovolemia, such as lactate and oliguria, fluid therapy has been demonstrated to be ineffective in improving the microcirculatory perfusion $[107,108]$. Using the optimization

Table 3 Presumed microcirculatory changes identified via hand-held videomicroscopy for the various types of hemodynamic coherence loss

\begin{tabular}{lllll}
\hline & Type 1 & Type 2 & Type 3 & Type 4 \\
\hline FCD & $\downarrow$ & $\downarrow$ & $\downarrow$ & $\downarrow \downarrow \downarrow$ \\
Tube Ht & $=$ & $\downarrow \downarrow \downarrow$ & $=/ \uparrow$ & $=$ \\
Discharge Ht & $\downarrow \uparrow$ & $\downarrow \downarrow$ & $\downarrow \downarrow \downarrow$ & $=$ \\
$\mathrm{HI}$ & $\uparrow \uparrow \uparrow$ & $=$ & $=$ & $=$ \\
\hline
\end{tabular}

Type 1, flow heterogeneity; type 2, hemodilution; type 3, constriction tamponade; type 4, edema. See text for further information FCD functional capillary density, $H t$ hematocrit, $H I$ heterogeneity index of the microcirculatory flow to achieve maximum oxygen transport to tissues as an end point, it has been proposed to administer fluids only following the indication of a low discharge hematocrit as the ultimate definition of hypovolemia. However, when the functional capillary density decreases, fluid administration should be terminated to avoid a type 2 loss of $\mathrm{HC}$ [1]. Similarly, microcirculatory-guided therapy has been proposed for the treatment of hypotension by vasopressor therapy. It has been demonstrated that only a low functional capillary density associated with hypotension responded to vasopressor therapy in the presence of a normal or high functional capillary density, despite the finding that the presence of hypotension vasopressor therapy did not improve the microcirculatory flow [83, 84]. These are examples of microcirculatory-guided fluid therapy that may be applicable to pediatric patients, although they must be validated in critically ill pediatric patients first.

Information from the $\mathrm{MC}$ must be integrated with systemic hemodynamic monitoring to provide an integrative hemodynamic monitoring platform of the cardiovascular system to facilitate clinical decisions and the titration of therapies. More sensitive information may also be obtained by further development of hand-held videomicroscopy, such as a prolonged observation of a single microcirculatory unit, inclusion of extra wavelengths of light to measure the RBC oxygen saturation, and an increased magnification to visualize subcellular structures, such as the glycocalyx and tissue membrane junctions $[89,109,110]$. It is expected that with these developments, hand-held videomicroscopy will have substantial benefits, including an early, sensitive diagnosis of cardiovascular compromise and an optimization of therapeutic interventions that restore the function of the vulnerable $\mathrm{MC}$ in critically ill pediatric patients.

\section{Abbreviations \\ CO: Cardiac output; ECMO: Extracorporeal membrane oxygenation; FCD: Functional capillary density; HC: Hemodynamic coherence; MC: Microcirculation; NO: Nitric oxide; PDA: Patent ductus arteriosus; RBC: Red blood cell; SVR: Systemic vascular resistance}

\section{Authors' contributions}

JWK drafted the manuscript. DT and CI reviewed the manuscript. All authors have read and approved the final version of the manuscript.

\section{Competing interests}

Dr. Ince has developed sidestream dark field imaging and is listed as an inventor on related patents commercialized by MicroVision Medical (MVM) under a license from the Academic Medical Center (AMC). He has been a consultant and has held shares in MVM in the past; however, he no longer has shares in the company and has not been involved with this company for more than five years. Braedius Medical, a company owned by a relative of Dr. Ince, has developed and designed a hand-held microscope referred to as CytoCam-IDF imaging. Dr. Ince has no financial relation with Braedius Medical, i.e., has never owned shares or received consultancy or speaker fees from Braedius Medical. JWK and DT do not have competing interests. 


\section{Author details}

'Intensive Care and Department of Pediatric Surgery, Erasmus Medical Center - Sophia Children's Hospital, Postbox 2040, 3000 CA Rotterdam, The Netherlands. ${ }^{2}$ Department of Intensive Care, Erasmus MC, University Medical Center Rotterdam, 's-Gravendijkwal 230, 3015 CE Rotterdam, The Netherlands.

\section{Published online: 30 October 2016}

\section{References}

1. Ince C. Hemodynamic coherence and the rationale for monitoring the microcirculation. Crit Care. 2015;19 Suppl 3:S8.

2. Azhibekov T, Noori S, Soleymani S, Seri I. Transitional cardiovascular physiology and comprehensive hemodynamic monitoring in the neonate: relevance to research and clinical care. Semin Fetal Neonatal Med. 2014;19:45-53.

3. Rasanen J, Wood DC, Weiner S, Ludomirski A, Huhta JC. Role of the pulmonary circulation in the distribution of human fetal cardiac output during the second half of pregnancy. Circulation. 1996;94:1068-73.

4. Rasanen J, Wood DC, Debbs RH, Cohen J, Weiner S, Huhta JC. Reactivity of the human fetal pulmonary circulation to maternal hyperoxygenation increases during the second half of pregnancy: a randomized study. Circulation. 1998;97:257-62.

5. Noori S, Wlodaver A, Gottipati V, McCoy M, Schultz D, Escobedo M. Transitional changes in cardiac and cerebral hemodynamics in term neonates at birth. J Pediatr. 2012;160:943-8.

6. Walther FJ, Benders MJ, Leighton JO. Early changes in the neonatal circulatory transition. J Pediatr. 1993;123:625-32.

7. Rabi Y, Yee W, Chen SY, Singhal N. Oxygen saturation trends immediately after birth. J Pediatr. 2006;148:590-4.

8. Saugstad OD. Oxygen saturations immediately after birth. J Pediatr. 2006:148:569-70.

9. Top AP, Tasker RC, Ince C. The microcirculation of the critically ill pediatric patient. Crit Care. 2011:15:213.

10. Cattermole GN, Leung PY, Mak PS, Chan SS, Graham CA, Rainer TH. The normal ranges of cardiovascular parameters in children measured using the Ultrasonic Cardiac Output Monitor. Crit Care Med. 2010;38:1875-81.

11. Framson CM, LeLeiko NS, Dallal GE, Roubenoff R, Snelling LK, Dwyer JT. Energy expenditure in critically ill children. Pediatr Crit Care Med. 2007;8:264-7.

12. Parker MM, Shelhamer JH, Bacharach SL, Green MV, Natanson C, Frederick TM, et al. Profound but reversible myocardial depression in patients with septic shock. Ann Intern Med. 1984;100:483-90.

13. Parker MM, Shelhamer JH, Natanson C, Alling DW, Parrillo JE. Serial cardiovascular variables in survivors and nonsurvivors of human septic shock: heart rate as an early predictor of prognosis. Crit Care Med. 1987;15:923-9.

14. Feltes TF, Pignatelli R, Kleinert S, Mariscalco MM. Quantitated left ventricular systolic mechanics in children with septic shock utilizing noninvasive wall-stress analysis. Crit Care Med. 1994:22:1647-58.

15. Baylen BG, Ogata H, Ikegami M, Jacobs H, Jobe A, Emmanouilides GC. Left ventricular performance and contractility before and after volume infusion: a comparative study of preterm and full-term newborn lambs. Circulation. 1986;73:1042-9.

16. Rowland DG, Gutgesell HP. Noninvasive assessment of myocardial contractility, preload, and afterload in healthy newborn infants. Am J Cardiol. 1995;75:818-21.

17. Schiffmann $H$, Erdlenbruch $B$, Singer D, Singer S, Herting E, Hoeft A, et al. Assessment of cardiac output, intravascular volume status, and extravascular lung water by transpulmonary indicator dilution in critically ill neonates and infants. J Cardiothorac Vasc Anesth. 2002;16:592-7.

18. Pereira de Souza NE, Grousson S, Duflo F, Ducreux C, Joly H, Convert J, et al. Predicting fluid responsiveness in mechanically ventilated children under general anaesthesia using dynamic parameters and transthoracic echocardiography. Br J Anaesth. 2011;106:856-64.

19. Brierley J, Peters MJ. Distinct hemodynamic patterns of septic shock at presentation to pediatric intensive care. Pediatrics. 2008;122:752-9.

20. Lemson J, Nusmeier A, van der Hoeven JG. Advanced hemodynamic monitoring in critically ill children. Pediatrics. 2011;128:560-71.

21. Ceneviva G, Paschall JA, Maffei F, Carcillo JA. Hemodynamic support in fluid-refractory pediatric septic shock. Pediatrics. 1998;102:e19.

22. Mercier JC, Beaufils F, Hartmann JF, Azema D. Hemodynamic patterns of meningococcal shock in children. Crit Care Med. 1988;16:27-33.
23. Egan JR, Festa M, Cole AD, Nunn GR, Gillis J, Winlaw DS. Clinical assessment of cardiac performance in infants and children following cardiac surgery. Intensive Care Med. 2005;31:568-73

24. Tibby SM, Murdoch IA. Measurement of cardiac output and tissue perfusion. Curr Opin Pediatr. 2002;14:303-9.

25. Tibby S. Transpulmonary thermodilution: finally, a gold standard for pediatric cardiac output measurement. Pediatr Crit Care Med. 2008;9:341-2.

26. Rajaram SS, Desai NK, Kalra A, Gajera M, Cavanaugh SK, Brampton W, et al. Pulmonary artery catheters for adult patients in intensive care. Cochrane Database Syst Rev. 2013:CD003408. doi:10.1002/14651858.CD003408.pub3.

27. Shah MR, Hasselblad V, Stevenson LW, Binanay C, O'Connor CM, Sopko G, et al. Impact of the pulmonary artery catheter in critically ill patients: meta-analysis of randomized clinical trials. JAMA. 2005:294:1664-70.

28. Connors Jr AF, Speroff T, Dawson NV, Thomas C, Harrell Jr FE, Wagner D, et al. The effectiveness of right heart catheterization in the initial care of critically ill patients. SUPPORT Investigators. JAMA. 1996;276:889-97.

29. Lemson J, de Boode WP, Hopman JC, Singh SK, van der Hoeven JG. Validation of transpulmonary thermodilution cardiac output measurement in a pediatric animal model. Pediatr Crit Care Med. 2008:9:313-9.

30. de Boode WP. Cardiac output monitoring in newborns. Early Hum Dev. 2010;86:143-8.

31. Tibby SM, Murdoch IA. Monitoring cardiac function in intensive care. Arch Dis Child. 2003:88:46-52

32. Fernandez EG, Green TP, Sweeney M. Low inferior vena caval catheters for hemodynamic and pulmonary function monitoring in pediatric critical care patients. Pediatr Crit Care Med. 2004;5:14-8.

33. Bauer $P$, Reinhart $K$, Bauer M. Significance of venous oximetry in the critically ill. Med Intensiva. 2008:32:134-42.

34. Ince C, Sinaasappel M. Microcirculatory oxygenation and shunting in sepsis and shock. Crit Care Med. 1999:27:1369-77.

35. Dellinger RP, Levy MM, Rhodes A, Annane D, Gerlach H, Opal SM, et al. Surviving Sepsis Campaign: international guidelines for management of severe sepsis and septic shock, 2012. Intensive Care Med. 2013;39:165-228.

36. Carcillo JA. Capillary refill time is a very useful clinical sign in early recognition and treatment of very sick children. Pediatr Crit Care Med. 2012;13:210-2.

37. Fleming S, Gill P, Jones C, Taylor JA, Van den Bruel A, Heneghan C, et al. The diagnostic value of capillary refill time for detecting serious illness in children: a systematic review and meta-analysis. PLoS One. 2015;10:e0138155.

38. Tibby SM, Hatherill M, Murdoch IA. Capillary refill and core-peripheral temperature gap as indicators of haemodynamic status in paediatric intensive care patients. Arch Dis Child. 1999;80:163-6.

39. Allen M. Lactate and acid base as a hemodynamic monitor and markers of cellular perfusion. Pediatr Crit Care Med. 2011;12:S43-9.

40. De BD. Lactic acidosis. Minerva Anestesiol. 2003:69:281-4.

41. Morris KP, McShane P, Stickley J, Parslow RC. The relationship between blood lactate concentration, the Paediatric Index of Mortality 2 (PIM2) and mortality in paediatric intensive care. Intensive Care Med. 2012;38:2042-6.

42. Hatherill M, Waggie Z, Purves L, Reynolds L, Argent A. Mortality and the nature of metabolic acidosis in children with shock. Intensive Care Med. 2003:29:286-91.

43. Hatherill M, McIntyre AG, Wattie M, Murdoch IA. Early hyperlactataemia in critically ill children. Intensive Care Med. 2000;26:314-8.

44. Duke TD, Butt W, South M. Predictors of mortality and multiple organ failure in children with sepsis. Intensive Care Med. 1997:23:684-92.

45. Hindy-Francois C, Meyer P, Blanot S, Marque S, Sabourdin N, Carli P, et al. Admission base deficit as a long-term prognostic factor in severe pediatric trauma patients. J Trauma. 2009;67:1272-7.

46. Fine-Goulden MR, Durward A. How to use lactate. Arch Dis Child Educ Pract Ed. 2014;99:17-22.

47. Genzel-Boroviczeny O, Strotgen J, Harris AG, Messmer K, Christ F. Orthogonal polarization spectral imaging (OPS): a novel method to measure the microcirculation in term and preterm infants transcutaneously. Pediatr Res. 2002:51:386-91.

48. Top AP, Ince C, de Meij N, van Dijk M, Tibboel D. Persistent low microcirculatory vessel density in nonsurvivors of sepsis in pediatric intensive care. Crit Care Med. 2011;39:8-13.

49. Buijs EA, Verboom EM, Top AP, Andrinopoulou ER, Buysse CM, Ince C, et al. Early microcirculatory impairment during therapeutic hypothermia is associated with poor outcome in post-cardiac arrest children: a prospective observational cohort study. Resuscitation. 2014;85:397-404. 
50. Ince $C$. The microcirculation is the motor of sepsis. Crit Care 2005;9 Suppl 4:S13-9.

51. De BD, Donadello K, Sakr Y, Ospina-Tascon G, Salgado D, Scolletta S, et al. Microcirculatory alterations in patients with severe sepsis: impact of time of assessment and relationship with outcome. Crit Care Med. 2013;41:791-9.

52. Edul VS, Enrico C, Laviolle B, Vazquez AR, Ince C, Dubin A. Quantitative assessment of the microcirculation in healthy volunteers and in patients with septic shock. Crit Care Med. 2012;40:1443-8.

53. Trzeciak S, McCoy JV, Phillip DR, Arnold RC, Rizzuto M, Abate NL, et al. Early increases in microcirculatory perfusion during protocol-directed resuscitation are associated with reduced multi-organ failure at $24 \mathrm{~h}$ in patients with sepsis. Intensive Care Med. 2008;34:2210-7.

54. Tachon G, Harrois A, Tanaka S, Kato H, Huet O, Pottecher J, et al. Microcirculatory alterations in traumatic hemorrhagic shock. Crit Care Med. 2014;42:1433-41.

55. Hernandez G, Boerma EC, Dubin A, Bruhn A, Koopmans M, Edul VK, et al. Severe abnormalities in microvascular perfused vessel density are associated to organ dysfunctions and mortality and can be predicted by hyperlactatemia and norepinephrine requirements in septic shock patients. J Crit Care. 2013;28(4):538. e9-14.

56. Sakr Y, Dubois MJ, De BD, Creteur J, Vincent JL. Persistent microcirculatory alterations are associated with organ failure and death in patients with septic shock. Crit Care Med. 2004;32:1825-31.

57. Trzeciak S, Rivers EP. Clinical manifestations of disordered microcirculatory perfusion in severe sepsis. Crit Care. 2005;9 Suppl 4:S20-6.

58. Spronk PE, Zandstra DF, Ince C. Bench-to-bedside review: Sepsis is a disease of the microcirculation. Crit Care. 2004;8:462-8.

59. Trzeciak S, Dellinger RP, Parrillo JE, Guglielmi M, Bajaj J, Abate NL, et al. Early microcirculatory perfusion derangements in patients with severe sepsis and septic shock: relationship to hemodynamics, oxygen transport, and survival. Ann Emerg Med. 2007;49:88-98. 98

60. Weil MH, Tang W. Welcoming a new era of hemodynamic monitoring expanding from the macro to the microcirculation. Crit Care Med. 2007;35:1204-5.

61. Genzel-Boroviczeny O, Christ F, Glas V. Blood transfusion increases functional capillary density in the skin of anemic preterm infants. Pediat Res. 2004;56:751-5.

62. Kroth J, Weidlich K, Hiedl S, Nussbaum C, Christ F, Genzel-Boroviczeny O. Functional vessel density in the first month of life in preterm neonates. Pediatr Res. 2008;64:567-71.

63. Ergenekon E, Hirfanoglu IM, Turan O, Beken S, Gucuyener K, Atalay Y. Partial exchange transfusion results in increased cerebral oxygenation and faster peripheral microcirculation in newborns with polycythemia. Acta Paediatr. 2011;100:1432-6.

64. Groner W, Winkelman JW, Harris AG, Ince C, Bouma GJ, Messmer K, et al. Orthogonal polarization spectral imaging: a new method for study of the microcirculation. Nat Med. 1999:5:1209-12.

65. Slaaf DW, Tangelder GJ, Reneman RS, Jager K, Bollinger A. A versatile incident illuminator for intravital microscopy. Int J Microcirc Clin Exp. 1987:6:391-7.

66. Goedhart PT, Khalilzada M, Bezemer R, Merza J, Ince C. Sidestream Dark Field (SDF) imaging: a novel stroboscopic LED ring-based imaging modality for clinical assessment of the microcirculation. Opt Express. 2007;15:15101-14

67. Sherman H, Klausner S, Cook WA. Incident dark-field illumination: a new method for microcirculatory study. Angiology. 1971:22:295-303.

68. van Elteren HA, Ince C, Tibboel D, Reiss IK, de Jonge RC. Cutaneous microcirculation in preterm neonates: comparison between sidestream dark field (SDF) and incident dark field (IDF) imaging. J Clin Monit Comput. 2015;29:543-8

69. De BD, Hollenberg S, Boerma C, Goedhart P, Buchele G, Ospina-Tascon G, et al. How to evaluate the microcirculation: report of a round table conference. Crit Care. 2007;11:R101.

70. Top AP, Ince C, van Dijk M, Tibboel D. Changes in buccal microcirculation following extracorporeal membrane oxygenation in term neonates with severe respiratory failure. Crit Care Med. 2009;37:1121-4.

71. Top AP, van Dijk M, van Velzen JE, Ince C, Tibboel D. Functional capillary density decreases after the first week of life in term neonates. Neonatology. 2011;99:73-7.

72. Top AP, Ince C, Schouwenberg PH, Tibboel D. Inhaled nitric oxide improves systemic microcirculation in infants with hypoxemic respiratory failure. Pediatr Crit Care Med. 2011;12:e271-4.
73. Top AP, Buijs EA, Schouwenberg PH, van Dijk M, Tibboel D, Ince C. The microcirculation is unchanged in neonates with severe respiratory failure after the initiation of ECMO treatment. Crit Care Res Pract. 2012;2012:372956.

74. Buijs EA, Reiss IK, Kraemer U, Andrinopoulou ER, Zwiers AJ, Ince C, et al. Increasing mean arterial blood pressure and heart rate with catecholaminergic drugs does not improve the microcirculation in children with congenital diaphragmatic hernia: a prospective cohort study. Pediatr Crit Care Med. 2014;15:343-54.

75. Spronk PE, Ince C, Gardien MJ, Mathura KR, Oudemans-van Straaten HM, Zandstra DF. Nitroglycerin in septic shock after intravascular volume resuscitation. Lancet. 2002:360:1395-6.

76. Boerma EC, Mathura KR, van der Voort PH, Spronk PE, Ince C. Quantifying bedside-derived imaging of microcirculatory abnormalities in septic patients: a prospective validation study. Crit Care. 2005;9:R601-6.

77. Massey MJ, Shapiro NI. A guide to human in vivo microcirculatory flow image analysis. Crit Care. 2016;20:35.

78. Perera P, Kurban AK, Ryan TJ. The development of the cutaneous microvascular system in the newborn. Br J Derm. 1970;82(S5):86-91.

79. Stopfkuchen $\mathrm{H}$. Changes of the cardiovascular system during the perinatal period. Eur J Pediatr. 1987;146:545-9.

80. Guyton AC, Carrier Jr O, Walker J. Evidence for tissue oxygen demand as the major factor causing autoregulation. Circ Res. 1964;15:SUPPL-9.

81. Hiedl S, Schwepcke A, Weber F, Genzel-Boroviczeny O. Microcirculation in preterm infants: profound effects of patent ductus arteriosus. J Pediatr. 2010;156:191-6

82. Boerma EC, Ince C. The role of vasoactive agents in the resuscitation of microvascular perfusion and tissue oxygenation in critically ill patients. Intensive Care Med. 2010:36:2004-18.

83. Dubin A, Pozo MO, Casabella CA, Palizas Jr F, Murias G, Moseinco MC, et al. Increasing arterial blood pressure with norepinephrine does not improve microcirculatory blood flow: a prospective study. Crit Care. 2009;13:R92.

84. Jhanji S, Stirling S, Patel N, Hinds CJ, Pearse RM. The effect of increasing doses of norepinephrine on tissue oxygenation and microvascular flow in patients with septic shock. Crit Care Med. 2009:37:1961-6.

85. Nussbaum C, Haberer A, Tiefenthaller A, Januszewska K, Chappell D, Brettner F, et al. Perturbation of the microvascular glycocalyx and perfusion in infants after cardiopulmonary bypass. J Thorac Cardiovasc Surg. 2015;150:1474-81.

86. Schinagl CM, Mormanova ZH, Puchwein-Schwepcke A, Schmid I, Genzel-Boroviczeny $O$. The effect of red blood cell transfusion on the microcirculation of anemic children. Eur J Pediatr. 2016;175:793-8.

87. Weidlich K, Kroth J, Nussbaum C, Hiedl S, Bauer A, Christ F, et al. Changes in microcirculation as early markers for infection in preterm infants-an observational prospective study. Pediatr Res. 2009;66:461-5.

88. van Genderen ME, Klijn E, Lima A, de Jonge J, Sleeswijk VS, Voorbeijtel J, et al. Microvascular perfusion as a target for fluid resuscitation in experimental circulatory shock. Crit Care Med. 2014;42:e96-e105.

89. Atasever B, Boer C, Goedhart P, Biervliet J, Seyffert J, Speekenbrink R, et al. Distinct alterations in sublingual microcirculatory blood flow and hemoglobin oxygenation in on-pump and off-pump coronary artery bypass graft surgery. J Cardiothorac Vasc Anesth. 2011;25:784-90.

90. Yuruk K, Almac E, Bezemer R, Goedhart P, de Mol B, Ince C. Blood transfusions recruit the microcirculation during cardiac surgery. Transfusion. 2011;51:961-7.

91. Donati A, Damiani E, Luchetti M, Domizi R, Scorcella C, Carsetti A, et al. Microcirculatory effects of the transfusion of leukodepleted or non-leukodepleted red blood cells in patients with sepsis: a pilot study. Crit Care. 2014;18:R33.

92. Trzeciak S, Glaspey LJ, Dellinger RP, Durflinger P, Anderson K, Dezfulian C, et al. Randomized controlled trial of inhaled nitric oxide for the treatment of microcirculatory dysfunction in patients with sepsis. Crit Care Med. 2014;42:2482-92.

93. Cabrales P, Tsai AG. Plasma viscosity regulates systemic and microvascular perfusion during acute extreme anemic conditions. Am J Physiol Heart Circ Physiol. 2006;291:H2445-52.

94. Boerma EC, van der Voort PH, Ince C. Sublingual microcirculatory flow is impaired by the vasopressin-analogue terlipressin in a patient with catecholamine-resistant septic shock. Acta Anaesthesiol Scand. 2005:49:1387-90.

95. Orbegozo CD, Puflea F, Donadello K, Taccone FS, Gottin L, Creteur J, et al. Normobaric hyperoxia alters the microcirculation in healthy volunteers. Microvasc Res. 2015;98:23-8. 
96. Tsai AG, Cabrales P, Winslow RM, Intaglietta M. Microvascular oxygen distribution in awake hamster window chamber model during hyperoxia. Am J Physiol Heart Circ Physiol. 2003;285:H1537-45.

97. Vellinga NA, Ince C, Boerma EC. Elevated central venous pressure is associated with impairment of microcirculatory blood flow in sepsis: a hypothesis generating post hoc analysis. BMC Anesthesiol. 2013;13:17.

98. Hanson JP, Lam SW, Mohanty S, Alam S, Pattnaik R, Mahanta KC, et al. Fluid resuscitation of adults with severe falciparum malaria: effects on acid-base status, renal function, and extravascular lung water. Crit Care Med. 2013:41:972-81.

99. Maitland K, Kiguli S, Opoka RO, Engoru C, Olupot-Olupot P, Akech SO, et al. Mortality after fluid bolus in African children with severe infection. N Engl J Med. 2011;364:2483-95.

100. Maitland K, George EC, Evans JA, Kiguli S, Olupot-Olupot P, Akech SO, et al. Exploring mechanisms of excess mortality with early fluid resuscitation: insights from the FEAST trial. BMC Med. 2013;11:68.

101. Ince C, Mayeux PR, Nguyen T, Gomez H, Kellum JA, Ospina-Tascon GA, et al. The endothelium in sepsis. Shock. 2016;45:259-70.

102. Ince C, Mik EG. Microcirculatory and mitochondrial hypoxia in sepsis, shock, and resuscitation. J Appl Physiol (1985). 2016;120:226-35.

103. Mik EG, Johannes T, Fries M. Clinical microvascular monitoring: a bright future without a future? Crit Care Med. 2009:37:2980-1.

104. Vellinga NA, Boerma EC, Koopmans M, Donati A, Dubin A, Shapiro NI, et al. International study on microcirculatory shock occurrence in acutely ill patients. Crit Care Med. 2015;43:48-56.

105. Desjardins C, Duling BR. Microvessel hematocrit: measurement and implications for capillary oxygen transport. Am J Physiol. 1987;252:H494-503.

106. Duling BR, Desjardins C. Capillary hematocrit-what does it mean. Physiology. 1987;2:66-9.

107. Ospina-Tascon G, Neves AP, Occhipinti G, Donadello K, Buchele G, Simion D, et al. Effects of fluids on microvascular perfusion in patients with severe sepsis. Intensive Care Med. 2010;36:949-55.

108. Pranskunas A, Koopmans M, Koetsier PM, Pilvinis V, Boerma EC Microcirculatory blood flow as a tool to select ICU patients eligible for fluid therapy. Intensive Care Med. 2013;39:612-9.

109. Kurata T, Li Z, Oda S, Kawahira H, Haneishi H. Impact of vessel diameter and bandwidth of illumination in sidestream dark-field oximetry. Biomed Opt Express. 2015;6:1616-31.

110. Marini JJ, Gattinoni L, Ince C, Kozek-Langenecker S, Mehta RL, Pichard C, et al. A few of our favorite unconfirmed ideas. Crit Care. 2015;19 Suppl 3:S1.

111. D'Souza R, Raghuraman RP, Nathan P, Manyonda IT, Antonios TF. Low birth weight infants do not have capillary rarefaction at birth: implications for early life influence on microcirculation. Hypertension. 2011;58:847-51.

112. Ergenekon E, Hirfanoglu I, Beken S, Turan O, Kulali F, Koc E, et al. Peripheral microcirculation is affected during therapeutic hypothermia in newborns. Arch Dis Child Fetal Neonatal Ed. 2013;98:F155-7.

113. Alba-Alejandre I, Hiedl S, Genzel-Boroviczeny O. Microcirculatory changes in term newborns with suspected infection: an observational prospective study. Int J Pediatr. 2013;2013:768784.

114. Schwepcke A, Weber FD, Mormanova Z, Cepissak B, Genzel-Boroviczeny O. Microcirculatory mechanisms in postnatal hypotension affecting premature infants. Pediatr Res. 2013;74:186-90.

115. Raghuraman RP, D'Souza R, Nathan P, Wang D, Manyonda IT, Antonios TF. Skin capillary density in infants born to normotensive mothers: a comparison between singleton and twin infants. Microcirculation. 2014;21:67-73.

116. van den Berg VJ, van Elteren HA, Buijs EA, Ince C, Tibboel D, Reiss IK, et al. Reproducibility of microvascular vessel density analysis in Sidestream dark-field-derived images of healthy term newborns. Microcirculation. 2015;22:37-43.

117. Paize F, Sarginson R, Makwana N, Baines PB, Thomson AP, Sinha I, et al. Changes in the sublingual microcirculation and endothelial adhesion molecules during the course of severe meningococcal disease treated in the paediatric intensive care unit. Intensive Care Med. 2012;38:863-71. 